\title{
The role of male coloration and ornamentation in potential alternative mating strategies of the dimorphic jumping spider, Maevia inclemens
}

\author{
Laurel B. Lietzenmayer ${ }^{1}$ - David L. Clark ${ }^{2} \cdot$ Lisa A. Taylor ${ }^{1,3}$ \\ Received: 21 November 2018 /Revised: 14 March 2019 / Accepted: 17 April 2019 / Published online: 27 May 2019 \\ (C) The Author(s) 2019
}

\begin{abstract}
Polymorphism can arise across taxa due to various selection pressures and potentially lead to alternative mating or antipredator strategies. For male jumping spiders, sexual selection and predation risk are often intertwined when courting cannibalistic females and may be a driving factor in the polymorphism of the jumping spider, Maevia inclemens. The dimorphic males of M. inclemens differ dramatically in their complex courtship behavior and display traits that may function as alternative mating strategies to reduce female aggression and maximize mating success. We hypothesized that males of the "tufted" morph honestly communicate condition or body size to females with three conspicuous tufts of setae on their head and males of the "striped" morph reduce female aggression with coloration commonly found in aposematic animals (here, yellow-orange pedipalps and striped legs). We examined correlations between tuft length and symmetry and metrics of body size and condition in fieldcollected spiders and conducted prey color choice tests (with live color-manipulated prey) to determine if yellow-orange and striped prey are avoided. Tuft length was variable and correlated with male size (but not condition). All prey color types were attacked at equal rates, but spiders oriented to striped prey more often, suggesting that male stripes may attract female attention without increasing predation. This study provides insight into the potential functions of the different courtship and visual displays of $M$. inclemens males. Using jumping spiders to study polymorphism can provide new insight into how multiple morphs can evolve, as males use mating strategies not only to impress females but also avoid getting eaten by their potential mates.
\end{abstract}

\section{Significance statement}

Understanding the selection pressures that shape and maintain polymorphisms in natural populations is an active area of inquiry, yet most of what we know comes from a small handful of well-studied vertebrate taxa. The unique biology of jumping spiders and the fact that males have to avoid cannibalism during courtship, makes them well-suited to provide novel insights into the functions and maintenance of dimorphic male traits. The unusual male dimorphism of $M$. inclemens captured the attention of naturalists as early as the 1800 s, yet we still do not understand why the two male morphs differ so dramatically in morphology and courtship behavior. Here, we propose and test a novel hypothesis that provides insight into the long-studied but still largely unexplained phenomenon of male dimorphism in this species.

Keywords Honest signal $\cdot$ Sexual cannibalism $\cdot$ Courtship strategy $\cdot$ Polymorphism $\cdot$ Visual signal

Communicated by J. Pruitt

Laurel B. Lietzenmayer

lblietzenmayer@ufl.edu

1 Entomology and Nematology Department, University of Florida, Gainesville, FL 32608, USA

2 Department of Biology, Alma College, Alma, MI 48801, USA

3 Florida Museum of Natural History, University of Florida, Gainesville, FL 32608, USA

\section{Introduction}

Polymorphism, the occurrence of two or more distinct variants within a population, has been observed across taxa; in many cases, such morphs differ drastically in behavioral and morphological characteristics (Gray and McKinnon 2007). Different morphs of the same species can potentially exploit alternative resources or employ different antipredator strategies (Fisher 1930; Galeotti et al. 2003; Roulin 2004). In the context of sexual selection, polymorphism can arise in the 
form of male alternative mating strategies. A wide variety of species use alternative mating strategies that allow different types of males to maximize their own mating success, the most prominent examples being species with large territorial males and smaller "sneaker" males that would not be as reproductively successful if they directly competed with dominant males (Zamudio and Sinervo 2000; Roulin 2004; Corl et al. 2010; Buzatto and Machado 2014).

Many studies of polymorphism (such as those described above) implicate a strong selection source that derives from either sexual selection or predation pressure. Jumping spiders (Family Salticidae) are a particularly intriguing system in which to study polymorphism because sexual selection and predation risk are closely intertwined as males often court larger (potentially cannibalistic) females that can be either mates or predators (Richman and Jackson 1992; Jackson and Pollard 1997). Jumping spiders have been extensively studied for their species-specific male courtship displays and elaborate coloration and ornamentation; such male displays have been hypothesized to mediate male-male interactions (Jackson and Cooper 1991; Lim and Li 2004; Tedore and Johnsen 2014) or to provide honest information used in female choice (Lim et al. 2008; Sivalinghem et al. 2010; Taylor et al. 2011; Taylor and McGraw 2013). Sexual cannibalism, where females consume males either before or after mating, is also prevalent among many jumping spider species and likely plays a large role in the mating strategies of males (Richman and Jackson 1992; Jackson and Pollard 1997). From the female's perspective, courting males are simultaneously assessed as potential mates and potential meals. For males, this results in a complex interaction between maximizing mating success and mitigating predation that may contribute to the evolution and maintenance of different courtship and antipredator strategies.

Despite the striking diversity of the family Salticidae (with more than 6000 species) (Platnick 2018), Maevia inclemens Walckenaer 1837 is the only jumping spider species known to have such extreme dimorphic males (Clark and Uetz 1990). This unique aspect of their biology, as well as the charismatic displays of the two different male morphs, captured the attention of naturalists as early as the 1800s (Peckham 1889; Painter 1913). Both males are of the same size (Busso and Rabosky 2016), but the "tufted morph" is characterized by three prominent tufts of setae on the front of the head, a black body, and white legs (Fig. 1a, b) while the "striped morph" (also referred to as the "gray morph" in the literature) has conspicuous yellow-orange pedipalps and black-and-white striped legs (Clark and Uetz 1993; Clark and Morjan 2001; Fig. 1c, d). The dimorphic males also have distinct courtship displays, with tufted males courting from afar and lifting tall while swinging their abdomen side to side, while striped males approach females at a closer distance and crouch down while moving in a zigzag pattern (Clark 1994). No intermediate morphs have been observed (Clark and Uetz 1992), and multiple studies thus far suggest that the reproductive success for both morphs is relatively equal, as females do not appear to show a preference for either morph (Clark and Uetz 1990; Clark and Uetz 1993; Clark and Morjan 2001; Clark and Biesiadecki 2002). It has been suggested that the different male morphs attain equal levels of mating success while courting at different distances from the female (i.e., tufted males farther away and striped males closer), because both courtship displays are similar in height and visual area relative to the target female (Clark and Uetz 1993; Clark and Morjan 2001; Clark and Biesiadecki 2002). It has also been suggested that disruptive selection may be driving male dimorphism in $M$. inclemens because female preference for male size and body condition differs between the male morphs (see below, Busso and Rabosky 2016). Predation risk from heterospecifics is also important to consider, as it has been shown that striped male courtship displays are more visually noisy than tufted male displays and put striped males at greater risk of being detected by predators (Clark et al. 2018). Despite this large body of work, it is still unclear why the two morphs are so vastly different from another in their specific courtship behavior and display traits. More specifically, why do the tufted males have tufts and court from afar? And why do the striped males have conspicuous yellow-orange pedipalps and striped legs and court closer to females?

Here, we hypothesize that the distinctive courtship behavior and display traits of the two morphs of $M$. inclemens reflect alternative mating strategies that maximize a male's reproductive success during courtship while simultaneously reducing the risk of predation from the female. Because these two courtship strategies that we propose are so different from one another, we describe each one separately in detail below.

Courtship strategy of the tufted morph: tufts as honest signals of size and/or body condition We hypothesize that the tufted morph's strategy relies heavily on females making assessments about a male based on his courtship display, with the display (and specifically, the size and symmetry of the conspicuous tufts) accurately communicating honest information about his potential quality as a mate. This content-based hypothesis (see Hebets and Papaj 2005) is consistent with data from previous studies on the courtship behavior of tufted males and female responses. Specifically, tufted males court females from far away $(86 \pm 6.8(\mathrm{~mm} \pm \mathrm{SEM}))$, remaining relatively stationary, stilting up tall and swinging their abdomens from side to side (Clark and Uetz 1993), giving females ample opportunity to assess these males. When presented with tufted males, there is evidence that females are assessing male courtship and exhibiting a preference for larger individuals in better body condition (Busso and Rabosky 2016). It is common for females to choose males based on size and body condition in other jumping spider species (Sivalinghem et al. 2010; Taylor 
Fig. 1 Adult male morphs of M. inclemens. a, b The tufted morph. c, $\mathbf{d}$ The striped morph

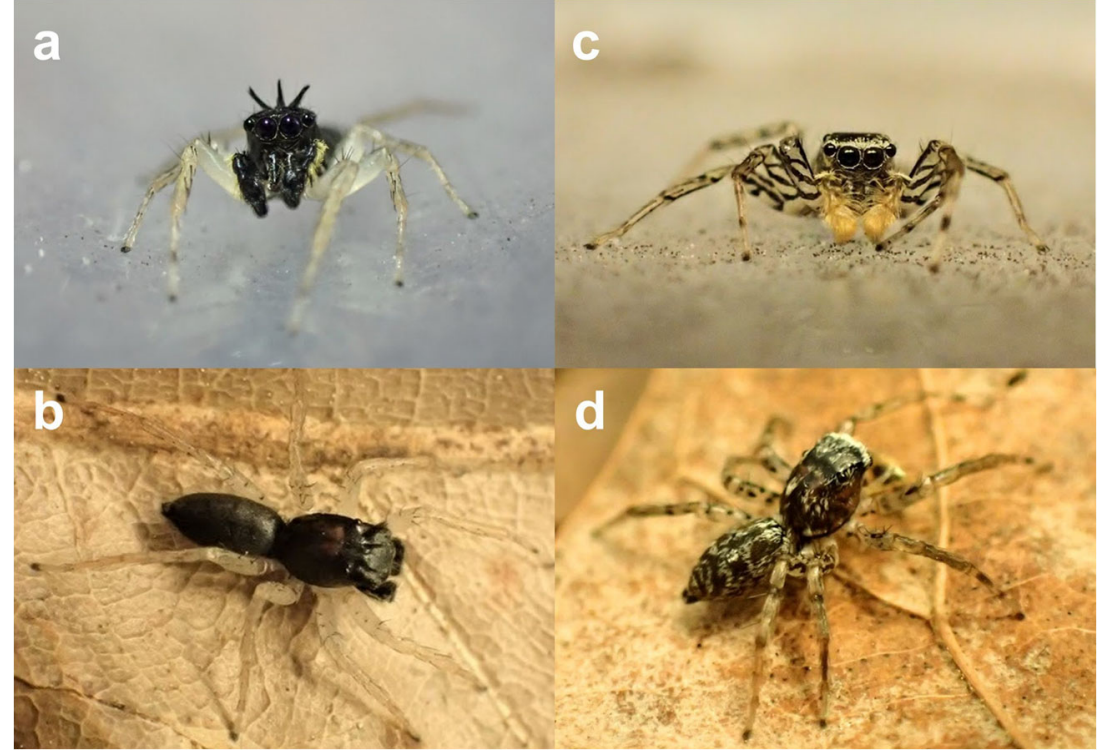

and McGraw 2013), as well as many other animal taxa (e.g., passerines (Wells et al. 2014), fish (Amorim et al. 2015), lizards (Martín and López 2015)). This is not surprising as both traits may indicate that a male is good at foraging and/or in good health (Uetz et al. 2002; Kapustjanskij et al. 2007). There is also evidence that, when tufted males are courting females, overly eager males that begin courting quickly or frequently have lower relative mating success than males that take longer and court females cautiously and less frequently (Busso and Rabosky 2016). This suggests that females are not being coerced by overly aggressive courtship from tufted males, but rather that these males are allowing females to choose and that females are making predictable choices for large males in better condition. However, it is not yet clear what specific cues females are using to select these larger, better-condition males (over smaller males in poorer condition).

We propose that the conspicuous tufts of these males are well-suited to honestly signal a male's size or condition (two traits that appear to be important to females, Busso and Rabosky 2016). These tufts are conspicuous and prominently displayed to females during courtship (see Fig. 1a). As such, the tufts may be relatively easy for females to assess, allowing for improved accuracy of response as females of this species make mate choice decisions rather quickly (Clark and Uetz 1992). If larger males have larger tufts, and if these tufts are sturdy structures that do not wear down over the course of the mating season, then they may be a consistent and reliable indicator of a male's size. However, an alternative is that because these tufts are produced only once in a male's lifetime (at sexual maturity) and cannot be repaired if damaged, they may undergo wear and breakage over the mating season; if this is the case, they may be less indicative of a male's size, but rather tuft size and/or tuft asymmetry may be good indicators of a male's current health status or body condition. These two scenarios provide clear and testable predictions. For both scenarios, we would expect attributes of the male's tufts (e.g., tuft length and/or tuft symmetry) to be variable enough among males in a population that females could detect such differences and could therefore use this information to separate preferred males from non-preferred males. If male tufts provide information about male body size, we would expect tuft length to correlate positively with body size, and we would expect that tuft length should not change over the breeding season so that they remain a consistent (and reliable) indicator of male size. Alternatively, if tufts provide information about a male's body condition, we would expect tuft length and/or tuft asymmetry to correlate positively with a male's current body condition. We might also expect tuft length and tuft asymmetry to decline over the course of the mating season (due to wear and breakage). After establishing the potential information content of the tufts in this present study, future manipulative mate choice experiments will allow further testing of their signaling function by asking whether females are indeed using these tufts to make mating decisions.

\section{Courtship strategy of the striped morph: color patterns as} deterrents of sexual cannibalism and aggression In contrast to the tufted male's strategy, we hypothesize that the striped males use a different courtship strategy that exploits female attention to and aversion toward specific colors in foraging, allowing them to court females more aggressively at close range. Compared to the tufted morph, the striped morph on average courts significantly closer to the female (striped: $34 \pm$ $3(\mathrm{~mm} \pm \mathrm{SEM})$; tufted $86 \pm 6.8(\mathrm{~mm} \pm \mathrm{SEM}))$; when close to the female, the striped male has been shown to be significantly faster at attracting her attention (Clark and Uetz 1993; Clark and Biesiadecki 2002). The striped morph also has bright 
yellow-orange pedipalps and conspicuous black-and-white stripes on the fronts of the legs that are displayed to females (see Fig. 1c, d), and crouches down while moving back and forth during courtship (Clark and Uetz 1993). The conspicuous yellow-orange pedipalps and black-and-white striped legs of these males are similar in color pattern to those of many aposematic prey species that capture the attention of predators and help to divert attacks (Ruxton et al. 2004). We know that females of several jumping spider species will avoid yelloworange and/or black-and-white striped prey even if they are more conspicuous than other prey colors. Specifically, Habronattus pyrrithrix attacks yellow (as well as red) prey at lower rates compared to other colors (Taylor et al. 2014). Experiments with Habronattus trimaculatus, Phidippus regius, and Plexippus paykulli using artificially striped prey suggest that black-and-white striped prey are often more conspicuous to the spiders (compared with non-striped prey), but receive fewer attacks (L. Gawel, M. Brock, E. Humbel, and L. Taylor, unpublished data). Because $M$. inclemens has a spectral sensitivity ranging from UV $(330 \mathrm{~nm})$ to red $(700 \mathrm{~nm})$ (Peaslee and Wilson 1989), females could potentially have this same aversion to yellow-orange and/or striped prey (although their ability to discriminate long-wavelength colors from those of shorter wavelengths is still unknown, see Peaslee and Wilson 1989).

If female M. inclemens avoid attacking striped and/or yellow-orange prey, striped males may be using their color patterns to suppress the female's predatory behavior and thus to reduce their risk of aggression and cannibalism during courtship. While foraging and mating are two distinct behavioral contexts in most animals, these two contexts overlap in taxa that are cannibalistic as females must simultaneously assess males as potential mates and/or potential prey (Johnson and Sih 2005); as such, heightened attention to and caution before attacking striped and/or yellow-orange prey in foraging could spill over from one context to another and lead to reduced attacks on striped/yellow-orange males during courtship interactions. Because striped males court significantly closer to females compared to tufted males, they may benefit from mechanisms of cannibalism-avoidance that yelloworange coloration and black-and-white stripes provide (see discussion in Clark et al. 2018). Interestingly, when videos of either male morph are presented to females on a computer monitor (courting at close range, $\sim 4 \mathrm{~cm}$ ), tufted males seem to receive more aggression from females than striped males (Clark and Morjan 2001; Clark and Biesiadecki 2002). In contrast to the tufted morph and most other species of jumping spiders (e.g., Habronattus dossenus: Elias et al. 2003; Cosmophasis umbratica: Lim and Li 2007; Habronattus pyrrithrix: Taylor et al. 2014), striped males that are smaller and in poorer condition are most successful in courtship (Busso and Rabosky 2016), suggesting that the striped morph may be exploiting females without honestly advertising their body size and condition. Unlike the relatively cautious tufted males, striped males can also increase their mating success by beginning courtship faster and courting more frequently (Busso and Rabosky 2016); coloration displayed during courtship may facilitate this more persistent/aggressive strategy.

This exploitation hypothesis for the striped male's color patterns focuses on the idea that females attend to and respond to certain conspicuous color patterns, even if these colors do not necessarily contain valuable information (see efficacybased strategies reviewed in Hebets and Papaj 2005). Like male traits of other spider taxa (Suter and Renkes 1984; Xiao et al. 2015), the striped male's coloration may act to suppress female aggression and predation. If these color patterns have a general aversive quality, we would predict that females should show reduced attacks on these same colors in the context of foraging (even if we expect these colors to be more conspicuous). More specifically, we would expect $M$. inclemens to show reduced predation, and take longer to attack, artificially colored yellow-orange and black-and-white striped prey items (compared to prey of other colors). If we do indeed find evidence that these colors act to suppress predation (in a foraging context), then future experiments could involve manipulating these colors on striped males and assessing the effects on female aggression and cannibalism risk.

The goal of this study was to test the idea that the sexual display traits of the dimorphic males of $M$. inclemens do indeed function as alternative mating strategies, as described above. To determine if tufted males might be using their tufts as honest signals of size or condition, we tested for positive correlations between tuft length, tuft symmetry, and male size and a residual body condition index in field-collected spiders. We also tested for consistency of tuft size and symmetry over the mating season (i.e., whether male tufts were consistent in size/symmetry throughout the season, or whether they declined in size/symmetry as would be expected if they undergo wear and breakage). To test our hypothesis about the color patterns of striped males acting to suppress female predation, we conducted prey choice experiments using colormanipulated termites to determine if females would avoid attacking yellow-orange or black-and-white striped prey. Our study tests novel hypotheses for the functions of the two starkly different male morphs of $M$. inclemens; this work provides insight into the long-studied, but still largely unexplained, differences between the morphs.

\section{Methods}

Collection and maintenance of study species Maevia inclemens Walckenaer 1837 is found throughout eastern and mid-western North America (Bradley 2012), commonly found along bike and hiking trails on vines and ivy. They 
are often found specifically on poison ivy (Toxicodendron radicans) and wintercreeper (Euonymus fortunei) (L. Lietzenmayer and Z. Burns, unpublished data). In previous studies, both male morphs have been found within the same microhabitat in equal frequencies (Clark and Uetz 1992).

We collected $M$. inclemens $(N=218 ; 65$ adult striped males, 43 adult tufted males, 78 adult females, and 32 juveniles) from multiple field sites in Northern Kentucky and Cincinnati, OH, USA, during the reproductive season (mid-May to mid-June 2017). Individuals were housed in plastic cylindrical vials $(2 \mathrm{~mm}$ diameter $\times 5.5 \mathrm{~mm}$ height) until being transferred to clear plastic rectangular boxes $(5.5 \mathrm{~mm}$ length $\times 5.5 \mathrm{~mm}$ width $\times 12.5 \mathrm{~mm}$ height) in the laboratory. The temperature was maintained at approximately $25{ }^{\circ} \mathrm{C}$, and light was provided from a combination of artificial fluorescent lights on a 12-h light/dark cycle supplemented with natural light from an adjacent window. Each box was enriched with an artificial green plant (Ashland Fern Collection, Michael's Stores, Irving, TX, USA) glued to the side of the box, and boxes were separated by an opaque white barrier to minimize interaction between neighboring spiders. Spiders were fed house crickets (Gryllodes sigillatus) in an amount equivalent to each spider's body size and provided with a spray of water three times per week. Each spider also had a watered cotton ball at the bottom of the container to provide extra humidity. All boxes were cleaned weekly by replacing the bottom lid of the box and replacing the watered cotton ball.

Tufts as honest signals of size and/or body condition To test the predictions described above regarding the tufts of setae on the tufted morph, we measured tuft length, tuft symmetry, body size, and body condition (using a residual condition index, see below) from field-collected tufted males. Tufted males that were caught by sweep net in the field were immediately placed in a small cylindrical glass vial with a flat bottom (5 $\mathrm{mm}$ tall and $1.5 \mathrm{~mm}$ in diameter). Photographs were taken of tufted male faces from the bottom of the vial to minimize distortion of the curved edges of the vial. Using Adobe Photoshop CC, we measured the relative length of each tuft (left tuft, middle tuft, and right tuft) as a proportion of the length between the anterior lateral eyes; this "relative tuft length" metric tells us how long a male's tufts are relative to his own individual body size. We used the spider's actual body size (from measurements of the carapace width of each spider taken from separate overhead photographs, as described in more detail below) to convert relative tuft lengths to absolute tuft length for each male. After taking these measures on each of the male's three tufts, we calculated a mean tuft length (both relative and absolute) for each male. Tuft symmetry was quantified by taking the absolute value of the difference between the length of the two side tufts (symmetry $=\mid$ right tuft-left tuft $\mid)$. Photographs that were not completely head-on $(n=9$ out of 43) were discarded and excluded from analyses to avoid inaccurate measurements. All field photographs were taken with an Olympus Tough TG-5 12.0-Megapixel digital camera using the built-in macro lens.

Tufted male body size and residual body condition index were calculated from overhead photographs also taken in the field immediately when each spider was caught. To take these photographs, spiders were individually placed in a small Ziploc bag and placed flat on top of $1 \mathrm{~mm}$ grid paper. In Adobe Photoshop CC, body size was calculated by measuring carapace width directly posterior to the anterior lateral eyes using the $1 \mathrm{~mm}$ grid as a reference measurement. Carapace width is a reliable indicator of structural body size in spiders (Jakob et al. 1996) and, in jumping spiders, this does not change once spiders reach maturity. To calculate the residual body condition index, we used this carapace width measurement and an abdomen area measurement taken from the same photographs in Photoshop CC. For each spider, we calculated a residual body condition index as described in Jakob et al. (1996). Spider abdomens stretch with feeding while carapace width is fixed at maturity, so this current body condition index provides a measure of how large a spider's abdomen is relative to its body size, or how "fat" the spider is (Jakob et al. 1996; Taylor et al. 2011; Taylor et al. 2014). Spiders that have recently fed, or who have had large meals, will have more positive condition indices than those who have not fed or who have had smaller meals. This is a commonly used metric of current body condition in spiders that often correlates with male display traits (Uetz et al. 2002; Hoefler et al. 2008).

Statistical analyses for male tuft data We examined variation in tuft length (relative and absolute) and tuft symmetry within our study population using descriptive statistics (mean, standard deviation, minimum, maximum, range, and interquartile range). We used linear regression to determine if relative tuft length or absolute tuft length correlated positively with male size (carapace width). We also used linear regression to determine if relative tuft length, absolute tuft length, or tuft symmetry correlated positively with residual body condition index. To determine if tuft length is constant throughout the entire reproductive season (as would be expected if it acts as a reliable and consistent indicator of body size) or decreases over the reproductive season (as would be expected if it signals a male's current condition index), we examined correlations between male relative tuft length, absolute tuft length, and symmetry and the date on which he was collected. Unlike many jumping spiders, $M$. inclemens has a very short and distinct reproductive season in our study area that ranges from mid-May to mid-June (Clark 1992); adult males and females are rarely collected outside of this range. Because our study was done using the same collection sites used in extensive 
previous work (Clark 1992), we can be confident that our sampling covered nearly the entire reproductive season.

Color patterns as deterrents of predation Field-collected spiders were used in prey color choice experiments between June and July 2017 ( $N=70,18$ adult striped males, 15 adult tufted males, and 36 adult females). We used termite workers Reticulitermes flavipes collected from logs in the University of Florida Natural Area Teaching Laboratory $\left(29^{\circ} 38^{\prime} 02.6^{\prime \prime} \mathrm{N}\right.$, $82^{\circ} 22^{\prime} 06.0^{\prime \prime} \mathrm{W}$ ) as prey items. Termites were given "capes" made from black-and-white striped, yellow-orange, or gray paper $(5 \times 2.5 \mathrm{~mm})$ that were adhered using Elmer's glue. The black-and-white striped and yellow-orange capes were used to represent the color patterns of striped males. Gray capes were used as a neutral colored prey item. Black-andwhite striped capes were standardized to always contain 3 black and 2 white alternating lines (see Fig. 3). Our goal was not to have the striped capes exactly mimic the dimensions of the stripes on the male spider's legs, but rather to help us assess whether black-and-white striped patterns generally (that are found on striped males, as well as a variety of aposematic prey) can help reduce attacks. Spectral measurements were recorded to compare the yellow-orange capes to the naturally colored yellow-orange pedipalps of the striped male using a UV-vis spectrophotometer (USB 2000+ with PX-2 pulsed xenon light source, Ocean Optics, Dunedin, FL) (Fig. 2). To take measurements, we freeze-killed ten fieldcollected striped males and removed one pedipalp per individual. The pedipalps were mounted with Elmer's glue to a microscope slide covered with matte black paper. We cut out size-matched pieces of the yellow-orange cape paper and gray cape paper and mounted them to separate microscope slides in the same way. Measurements of pedipalps and capes were recorded with the probe perpendicular to the sample and the

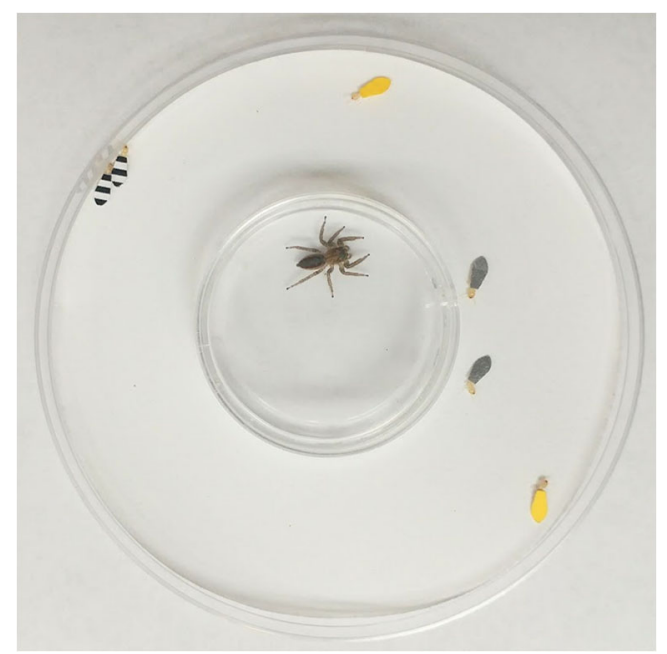

Fig. 3 Testing arena used in the prey color choice experiment consisting of six termites with three different colored capes (striped, yellow-orange, and gray) emitted light fully covering the colored surface. We recorded three measurements for each pedipalp and paper cutout. All measurements were relative to a Sprectralon diffuse white reflectance standard (Labsphere Inc., North Sutton, NH).

After 30 min of drying, six termites ( 2 black-and-whitestriped, 2 yellow-orange, 2 gray) were placed in a filterpaper-lined testing arena (9-mm-diameter petri dish) surrounded on all sides by a white paper background to prevent visual distractions (Fig. 3). Previous experiments have shown that the capes do not hinder normal movement of the termites, as there was no difference in movement rates between caped and uncaped termites (L. Gawel, M. Brock, and L. Taylor, unpublished data). Just prior to testing, an individual spider was placed in a smaller 3.5-mm-diameter petri dish in the center of testing arena to acclimate for $5 \mathrm{~min}$ (and view the surrounding termites). The spider was then released into the testing arena by removing the small petri dish lid. The spider was then allowed to forage freely on the six termites (always 2 black-and-white-striped, 2 yellow-orange, and 2 gray). After $10 \mathrm{~min}$, if the spider did not attack a prey item, the test was stopped, and the spider was re-tested on the following testing day. Each spider was only re-tested up to two times ( 3 trials total). If a spider attacked and captured a termite, the trial stopped, and the spider was not re-tested. Spiders were tested indoors in an area adjacent to two large corner windows $(1.5 \times$ $0.9 \mathrm{~m}$ and $2.8 \times 5.0 \mathrm{~m}$ ) where they were fully illuminated with natural sunlight. We did not run tests on cloudy or overcast days. Spiders were not fed within $24 \mathrm{~h}$ of testing. Termites were discarded after each test, and petri dishes were cleaned with ethanol to remove any olfactory cues from previous spiders or termites. All trials were recorded using a Sony Handycam HDR-PJ540. We recorded the number of times spiders oriented to each of the three colors, the color of termite

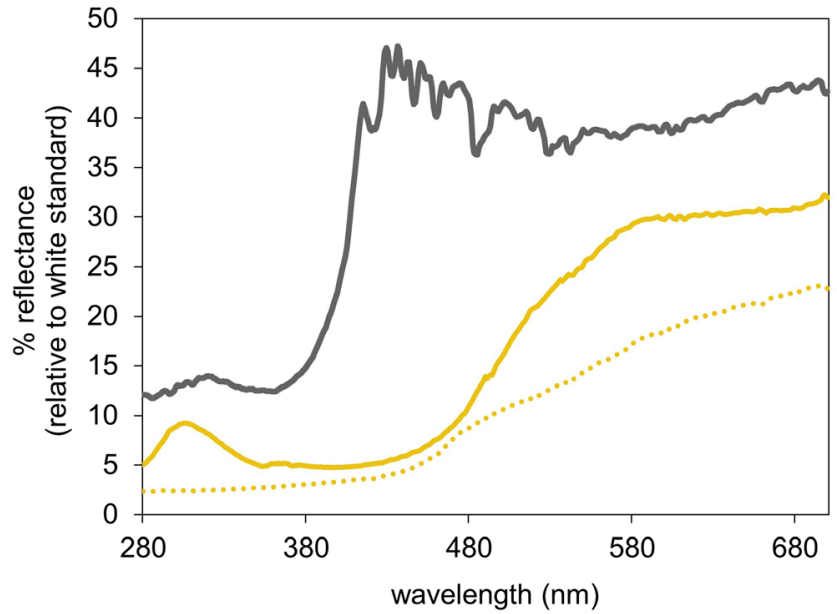

Fig. 2 Representative reflectance spectra of yellow-orange caped termites (solid yellow), natural yellow-orange pedipalps of the striped male Maevia inclemens (dotted yellow), and gray caped termites (solid gray). Curves represent the mean values of 10 individuals measured 3 times each 
attacked, and the latency to attack from the videos. While we did not use blinded methods in our data collection, these data were straightforward and unambiguous, and unlikely to suffer from biases. We defined an "orientation" as the spider quickly rotating its entire body so that its principle eyes directly faced a termite. This orientation behavior always precedes an attack, but spiders also frequently orient to objects and then decide not to attack (personal observation). As such, the number of orientations toward prey of each color can provide us with information about how conspicuous the three colors are to the spiders (regardless of whether they ultimately choose to attack them).

Statistical analyses for prey color choice tests We determined if certain colored termites were more likely to capture the spider's attention (i.e., eliciting more orientations) using a restricted maximum likelihood (REML) mixed model; because we had data on the orientations of each spider to the three different colors, we included spider ID as a random factor in the model. We used a Pearson's chi-square goodness-of-fit test to test the prediction that spiders would attack yellow-orange and striped prey at lower rates (compared with gray prey). A one-way analysis of variance (ANOVA) was performed to test if the latency to attack differed between the different colored termites. All statistical analyses were conducted using JMP Pro 13 for Windows (SAS Institute, Cary, NC, USA), and all figures were created using $\mathrm{R}$ version 3.4.4 for Windows.

Data Availability The datasets generated during and/or analysed during the current study are available in the Dryad Digital Repository: https://urldefense.proofpoint.com/v2/url? $\mathrm{u}=\mathrm{https}-3$ A_doi.org_10.5061_dryad.bb8kv5f\&d= DwICaQ\& $\mathrm{c}=\mathrm{sJ} 6 \mathrm{xIWYx}-\mathrm{zLMB} 3 \mathrm{EPkvenVg} \& \mathrm{r}=$ 1h0vgnFj8p_URYkCYIrBaQXk6pjljfGKj-SKL4 T R m M \& m = y p V L U C c D n e K 0 M J Q 4 k O

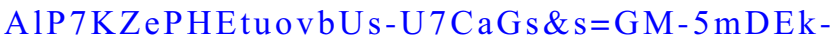
GLF97qPJRj-txdkeJY_pezH_LLD3Mb-wAs\&e=.

\section{Results}

Tufts as honest signals of size and/or body condition All three attributes of male tufts that we measured (relative tuft length, absolute tuft length, and tuft symmetry) showed variation in our field population (Table 1), suggesting that females could use this information to separate preferred males from non-preferred males, assuming they are able to detect it. Relative tuft length did not correlate with body size $\left(R^{2}=0.02, F_{1,33}=0.78, P=\right.$ 0.38 , Fig. 4a), but absolute tuft length was positively correlated with male body size (i.e., larger males had longer tufts, $\left(R^{2}=\right.$ $0.15, F_{1,33}=5.86, P=0.02$, Fig. $\left.4 \mathrm{~b}\right)$. Neither relative tuft length, absolute tuft length, nor tuft symmetry was correlated with residual body condition index (relative tuft length: $R^{2}=$ $0.002, F_{1,33}=0.07, P=0.79$, Fig. $4 \mathrm{c}$; absolute tuft length: $R^{2}=$ $0.004, F_{1,33}=0.13, P=0.72$, Fig. 4 d; tuft symmetry: $R^{2}=0.04$, $F_{1,33}=1.45, P=0.24$, Fig. $\left.4 \mathrm{e}\right)$. Neither relative tuft length, absolute tuft length, nor tuft symmetry changed throughout the breeding season (relative tuft length: $R^{2}=0.004, F_{1,33}=0.14$, $P=0.71$; absolute tuft length: $R^{2}=0.001, F_{1,33}=0.04, P=$ 0.84 ; tuft symmetry: $R^{2}=0.04, F_{1,33}=1.39, P=0.25$ ).

Color patterns as deterrents of predation Striped termites were oriented to nearly $38 \%$ more often than gray or yelloworange termites $\left(F_{2,203}=5.35, P=0.005\right.$, Fig. 5a). Overall attack rates did not differ between the three prey color choices (striped $=17$, yellow-orange $=18$, gray $=24 ; \chi^{2}=1.46, P=$ 0.48 , Fig. 5 b). When attacks did occur, there was no difference in attack latency between the three colors $\left(F_{2,58}=1.18, P=\right.$ $0.31)$.

\section{Discussion}

Here, we provide evidence for alternative courtship strategies in the dimorphic males of $M$. inclemens that improves our understanding of the functions behind the different courtship behavior and display traits. Our data are consistent with the idea that the three tufts of setae on the top of the head of the tufted male may be honest indicators of body size because tuft lengths are variable, correlate with body size, and their sizes remain constant throughout the breeding season. We also found evidence in support of the idea that the black-andwhite striped legs of the striped male may function to reduce sexual cannibalism while also grabbing the female's attention; in a prey color choice test with artificially colored prey, we found that termites with black-and-white stripes were more conspicuous to spiders (i.e., elicited more attention from the spiders) than either yellow-orange or gray termites. Yet, despite this increased conspicuousness (that we would expect should subsequently increase attacks on striped prey), we found that all three colors were attacked at similar rates.

Table 1 Variation among tuft attributes from field-caught tufted male $M$. inclemens $(N=34)$

\begin{tabular}{llllll}
\hline Tuft trait & Mean \pm SD & Max & Min & Range & Interquartile range \\
\hline Relative tuft length (relative to carapace width) & $0.41 \pm 0.04$ & 0.49 & 0.32 & 0.17 & 0.05 \\
Absolute tuft length (mm) & $0.79 \pm 0.08$ & 0.91 & 0.63 & 0.28 & 0.14 \\
Tuft symmetry (|right tuft-left tuft|) (mm) & $0.05 \pm 0.04$ & 0.13 & 0.002 & 0.13 & 0.07 \\
\hline
\end{tabular}


Fig. 4 Relationships between relative tuft length, absolute tuft length, tuft symmetry, carapace width, and body condition index from field caught tufted male M. inclemens. Regression lines indicate significant relationships. Note that for body condition indices, low values (below zero) indicate skinnier males relative to their body size while large values (above zero) indicate fatter males relative to their body size
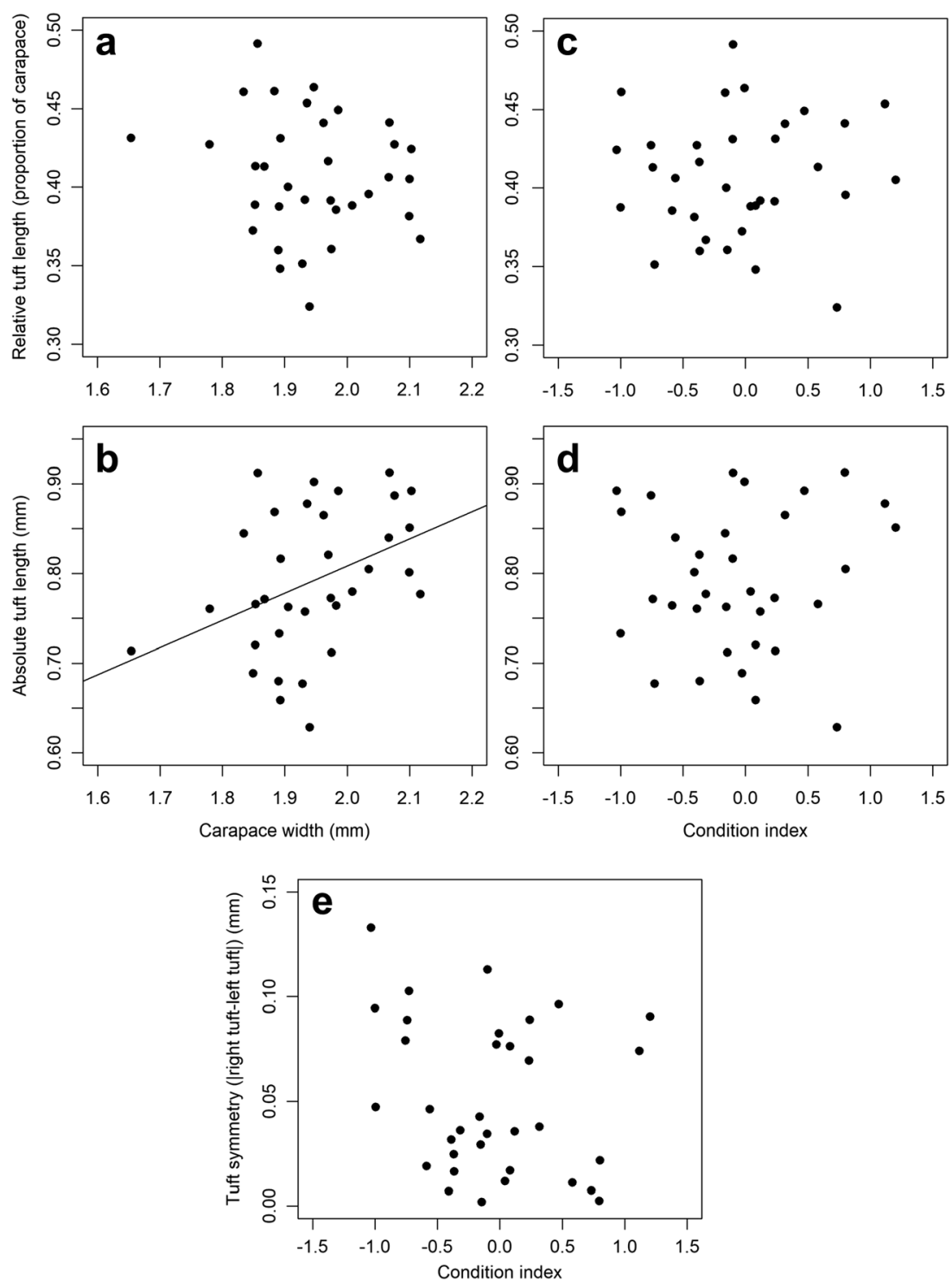

Tufts as potential honest signals of size and/or body condition We found that tuft length and symmetry do vary in the population. Assuming females can detect this variation, this should satisfy the first prediction for the use of tufts by courting males to communicate honest information to females. However, we do not have enough information to predict what the cutoff for female detection of this variation is, and therefore support for this first prediction carries only limited weight. What is more important is that we found a significant positive relationship between absolute tuft length and body size, suggesting that tufts could function as a redundant signal by providing an additional indicator of body size, improving female assessment of a courting male (Møller and Pomiankowski 1993; Johnstone 1996). Tufts are conspicuous and prominently displayed during courtship and could potentially be faster and easier to assess compared to assessing a male's size directly. This is potentially important from the perspective of both the female and male because females make mate choice decisions quickly (Clark and Uetz 1992).

Neither tuft length nor tuft symmetry was correlated with a male's current body condition (estimated using a residual body condition index). Additionally, mean tuft length and symmetry for the entire population do not change throughout the breeding season (as males age), suggesting that tufts may be resistant to significant wear and tear throughout the mating season. These pieces of information suggest that tufts are not likely to function to communicate a male's current body condition index during courtship. However, future studies should examine this idea further, perhaps by tracking condition and tuft attributes of individual males as they age. While not tested in the present study, it is also possible that attributes of the tufts may be linked to past condition during development. Juvenile development may be critically important if tuft length functions as a sexual signal because jumping spiders do not molt 

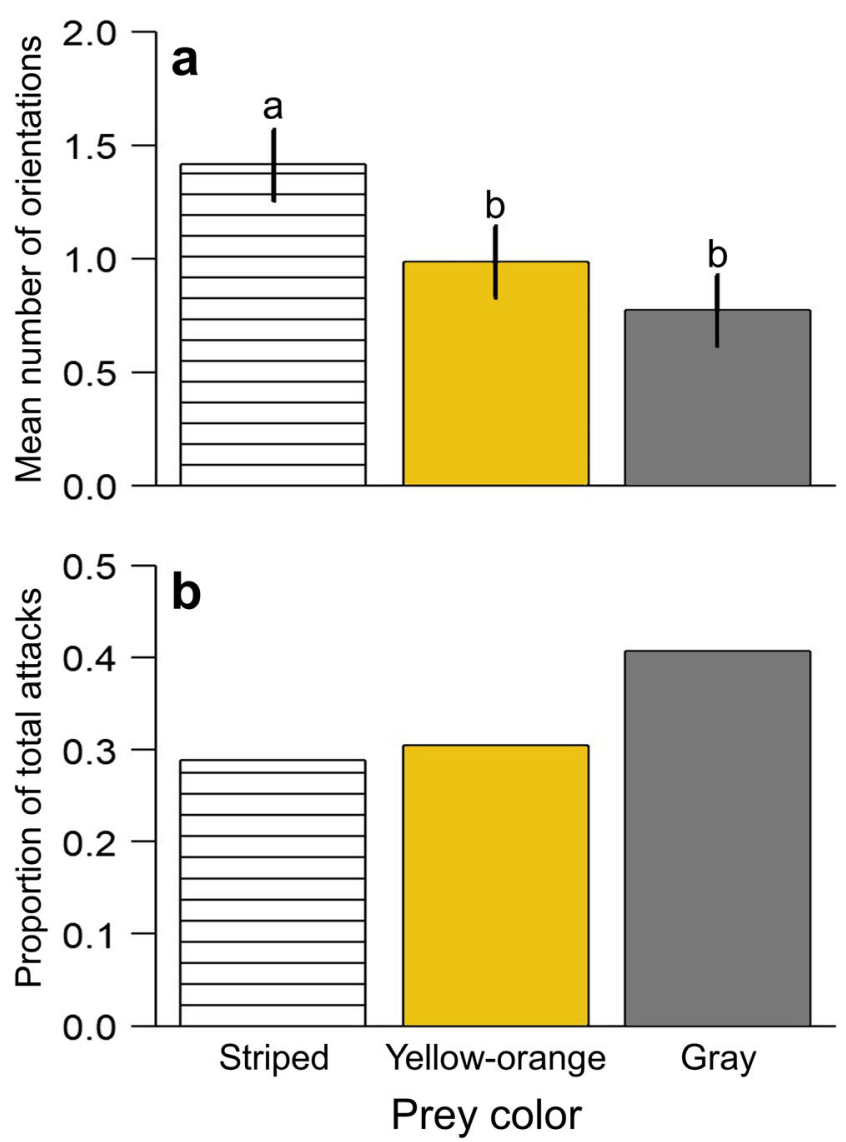

Fig. 5 Results of prey color choice experiments with adult male and female $M$. inclemens. a Differences in orientation frequencies to different colored termites (striped, yellow-orange, and gray). Error bars represent mean \pm SEM. Bars labeled with different letters are significantly different from one another. b Proportions of overall attacks on striped, yellow-orange, and gray termites

after maturity, and the setae that make up the tufts cannot grow between molts (Foelix 2011). Indeed, there is a large precedent in the literature for past developmental stress influencing adult sexual display traits in many taxa. For example, in zebra finches, the complexity of male songs is an indicator of past developmental stress (Spencer et al. 2003). The size of tufts of setae on the front legs of males used in visual displays in the wolf spider, Schizocosa ocreata, are affected by juvenile diet quality in that poorly fed juveniles tend to have shorter tufts as adults compared to well-fed juveniles (Uetz et al. 2002). Juvenile diet in the jumping spider, Habronattus pyrrithrix, has also been shown to affect the red facial coloration that males display to females in courtship (Taylor et al. 2011). Diet manipulation experiments in $M$. inclemens could help to determine if juvenile nutrition and condition influence tuft length and/or tuft symmetry at the final molt.

Color patterns as deterrents of predation Our sensory exploitation hypothesis that striped males use black-and-white striped legs to reduce female aggression and avoid cannibalism led to the a priori prediction that females should avoid attacking this color pattern while foraging. Indeed, our previous (unpublished) findings showing that three other jumping spider species avoid striped prey when foraging (described in the "Introduction") also contributed to this expectation. However, our prey color choice tests with $M$. inclemens showed that, contrary to this prediction, spiders attacked striped, yellow-orange, and gray prey equally. Interestingly though, they oriented to the striped prey far more often than the other two prey colors. Therefore, stripes appear to capture the attention of spiders without increasing the probability of attack. Intuitively, we would expect that higher orientation frequency should subsequently increase the probability of attack, and indeed, there is a large literature showing that increased conspicuousness of prey leads to increased predation across many taxa (e.g., lizards: Stuart-Fox et al. 2003, fish: Godin and McDonough 2003). It may be that black-and-white stripes indeed have an aversive quality in a foraging context that allows for enhanced conspicuousness without the expected increase in attacks. These data are perhaps most consistent with a modified version of our original hypothesis whereby the main function of the stripes in male $M$. inclemens is to attract and monopolize a female's attention; black-and-white stripes may be particularly well suited for this because they can successfully attract attention, without increasing attack. In a previous study with $M$. inclemens, it has been shown that striped males are more noticeable to predators during courtship at longer distances compared to tufted males (Clark et al. 2018). It may be that the striped legs of striped males are conspicuous to females during courtship when males are in their courtship pose, and also have the negative side effect of increasing a male's conspicuousness to predators. Yet, if there is something about these stripes that allows them to attract and hold female attention without a subsequent increase in attack rate (from either conspecifics, heterospecifics, or both), it may increase a male's success during the relatively aggressive close-up courtship strategy of the striped morph. Future experiments should examine whether black-and-white stripes outperform other colors and patterns at maximizing conspicuousness without increasing attack rate.

Interestingly, and contrary to our predictions, yelloworange termites were not as conspicuous as striped termites in our choice tests (i.e., test spiders did not orient to them as often). There is evidence that the principal eyes of $M$. inclemens have a broad spectral sensitivity extending from the UV $(330 \mathrm{~nm})$ to deep red $(700 \mathrm{~nm})$, but we do not yet know if these spiders can discriminate long-wavelength colors from shorter-wavelength colors (Peaslee and Wilson 1989). Such "true" color vision has been documented in other jumping spiders (e.g., Habronattus, see Zurek et al. 2015), but studies with $M$. inclemens are still lacking. To further understand any potential signaling function of the yelloworange pedipalps, future studies focusing on intraspecific interactions between males and females should be conducted. 
The present study offers compelling preliminary support for our hypotheses about the alternative mating tactics of tufted and striped morphs of $M$. inclemens. However, the crucial next step will be to conduct female mate choice studies that measure the mating success of males with manipulated display traits (i.e., the tuft lengths of tufted males and the striped legs and yellow-orange pedipalps of striped males, see Fig. 1) both within and beyond natural levels of variation. Both content-based and efficacy-based hypotheses for the function of signals require that the receiver pays attention to the signal in question (Guilford and Dawkins 1991; Hebets and Papaj 2005). Multiple previous studies with M. inclemens have suggested that males (regardless of morph) gain reproductive success by attracting female attention relatively quickly (Clark and Uetz 1992; Clark and Morjan 2001; Clark and Biesiadecki 2002); our findings may help explain how the specific strategies of each male improve his ability to communicate quickly with females. For tufted males, tuft length may function as a redundant signal for male size; if females pay attention to it, they may be able to streamline the assessment process. For striped males, stripes may function similarly in both foraging and courtship contexts by attracting the attention of females quickly (without increasing predation risk). One limitation of our study is that we asked separate questions for each of the morphs, leaving alternative hypotheses still to be considered. Our prior knowledge of the biology of each morph (outlined in detail in the "Introduction") led us to hypothesize that tufts function specifically in honest signaling, while black-and-white stripes and yellow-orange coloration function specifically in cannibalism reduction. However, future work should consider other alternatives, including the idea that the striped morph's colors may act as honest signals, or tufts may function in cannibalism reduction.

In this study, we add to the large and growing literature on how and why alternative male mating strategies exist across animal taxa (Taborsky and Brockmann 2010; Neff and Svensson 2013; Cummings and Ramsey 2015). We also add to the literature focused on the unusual dimorphism in M. inclemens (Painter 1913; Clark and Uetz 1990; Clark 1992; Clark and Uetz 1992; Clark and Uetz 1993; Clark 1994; Clark and Morjan 2001; Clark and Biesiadecki 2002; Busso and Rabosky 2016; Clark et al. 2018). To our knowledge, this study is the first to examine the functions of the specific display traits (tufts of the tufted morph and striped legs/yellow-orange pedipalps of the striped morph) of each male, and how they may be used in alternative courtship strategies. Beyond the genus Maevia, there are no other accounts of male dimorphism in the more than 6000 jumping spider species. The majority of what we know about the function and maintenance of male dimorphism comes from a small number of animal taxa (beetles: Emlen 1997; birds: Galeotti et al. 2003; Roulin 2004; lizards: Zamudio and Sinervo 2000; fish: Marentette et al. 2009); novel and unexpected insights might be uncovered using understudied groups such as jumping spiders (where dimorphism is rare), particularly because males must use mating strategies that not only impress females but also allow males to avoid getting eaten by their potential mates.

Acknowledgements C. Miller and two anonymous reviewers provided valuable feedback on earlier versions of this manuscript. We thank members of the Taylor lab for their feedback throughout this study. We would also like to thank Z. Burns and R. Murphy for their assistance in the field and lab and G. Uetz for assistance locating and accessing collection sites. Publication of this article was funded in part by the University of Florida Open Access Publishing Fund.

Funding information This work was supported by funding from a National Science Foundation grant (IOS-1557867 to L.A.T.), the Florida Museum of Natural History, and the Entomology and Nematology Department at the University of Florida.

Open Access This article is distributed under the terms of the Creative Commons Attribution 4.0 International License (http:// creativecommons.org/licenses/by/4.0/), which permits unrestricted use, distribution, and reproduction in any medium, provided you give appropriate credit to the original author(s) and the source, provide a link to the Creative Commons license, and indicate if changes were made.

\section{References}

Amorim MC, Vasconcelos RO, Fonseca PJ (2015) Fish sounds and mate choice. In: Ladich F (ed) Sound communication in fishes. Springer, Vienna, pp 1-33. https://doi.org/10.1007/978-3-7091-1846-7_1

Bradley RA (2012) Common spiders of North America. University of California Press, Berkeley

Busso JP, Rabosky AD (2016) Disruptive selection on male reproductive polymorphism in a jumping spider, Maevia inclemens. Anim Behav 120:1-10. https://doi.org/10.1016/j.anbehav.2016.07.028

Buzatto BA, Machado G (2014) Male dimorphism and alternative reproductive tactics in harvestmen (Arachnida: Opiliones). Behav Process 109:2-13. https://doi.org/10.1016/j.beproc.2014.06.008

Clark DL (1992) Male dimorphism and species recognition in the jumping spider, Maevia inclemens (Araneae: Salticidae). Dissertation, University of Cincinnati

Clark DL (1994) Sequence analysis of courtship behavior in the dimorphic jumping spider Maevia inclemens (Araneae, Salticidae). J Arachnol 22:94-107

Clark DL, Biesiadecki B (2002) Mating success and alternative reproductive strategies of the dimorphic jumping spider, Maevia inclemens (Araneae, Salticidae). J Arachnol 30:511-518. https://doi.org/10. 1636/0161-8202(2002)030[0511:MSAARS]2.0.CO;2

Clark DL, Morjan CL (2001) Attracting female attention: the evolution of dimorphic courtship displays in the jumping spider Maevia inclemens (Araneae: Salticidae). Proc R Soc B 268:2461-2465. https://doi.org/10.1098/rspb.2001.1819

Clark DL, Uetz GW (1990) Video image recognition by the jumping spider, Maevia inclemens (Araneae: Salticidae). Anim Behav 40: 884-890. https://doi.org/10.1016/S0003-3472(05)80990-X

Clark DL, Uetz GW (1992) Morph-independent mate selection in a dimorphic jumping spider: demonstration of movement bias in female choice using video-controlled courtship behaviour. Anim Behav 43: 247-254. https://doi.org/10.1016/S0003-3472(05)80220-9 
Clark DL, Uetz GW (1993) Signal efficacy and the evolution of male dimorphism in the jumping spider, Maevia inclemens. Proc Natl Acad Sci U S A 90:11954-11957. https://doi.org/10.1073/pnas.90. 24.11954

Clark DL, Simmons LA, Bowker RG (2018) Aspects of courtship risks and mating success in the dimorphic jumping spider, Maevia inclemens (Araneae: Salticidae). J Arachnol 46:1-6. https://doi. org/10.1636/JoA-S-16-029R2.1

Corl A, Davis AR, Kuchta SR, Sinervo B (2010) Selective loss of polymorphic mating types is associated with rapid phenotypic evolution during morphic speciation. Proc Natl Acad Sci USA 107:4254 4259. https://doi.org/10.1073/pnas.0909480107

Cummings ME, Ramsey ME (2015) Mate choice as social cognition: predicting female behavioral and neural plasticity as a function of alternative male reproductive tactics. Curr Opin Behav Sci 6:125131. https://doi.org/10.1016/j.cobeha.2015.10.001

Elias DO, Mason AC, Maddison WP, Hoy RR (2003) Seismic signals in a courting male jumping spider (Araneae: Salticidae). J Exp Biol 206: 4029-4039. https://doi.org/10.1242/jeb.00634

Emlen DJ (1997) Alternative reproductive tactics and male-dimorphism in the horned beetle Onthophagus acuminatus (Coleoptera: Scarabaeidae). Behav Ecol Sociobiol 41:335-341. https://doi.org/ $10.1007 / \mathrm{s} 002650050393$

Fisher RA (1930) The genetical theory of natural selection: a complete variorum edition. Oxford University Press, New York

Foelix RF (2011) Biology of spiders. Oxford University Press, New York

Galeotti P, Rubolini D, Dunn PO, Fasola M (2003) Colour polymorphism in birds: causes and functions. J Evol Biol 16:635-646. https://doi. org/10.1046/j.1420-9101.2003.00569.x

Godin JGJ, McDonough HE (2003) Predator preference for brightly colored males in the guppy: a viability cost for a sexually selected trait. Behav Ecol 14:194-200. https://doi.org/10.1093/beheco/14.2.194

Gray SM, McKinnon JS (2007) Linking color polymorphism maintenance and speciation. Trends Ecol Evol 22:71-79. https://doi.org/ 10.1016/j.tree.2006.10.005

Guilford T, Dawkins MS (1991) Receiver psychology and the evolution of animal signals. Anim Behav 42:1-14. https://doi.org/10.1016/ S0003-3472(05)80600-1

Hebets EA, Papaj DR (2005) Complex signal function: developing a framework of testable hypotheses. Behav Ecol Sociobiol 57:197214. https://doi.org/10.1007/s00265-004-0865-7

Hoefler CD, Persons MH, Rypstra AL (2008) Evolutionarily costly courtship displays in a wolf spider: a test of viability indicator theory. Behav Ecol 19:974-979. https://doi.org/10.1093/beheco/arn055

Jackson RR, Cooper KJ (1991) The influence of body size and prior residency on the outcome of male-male interactions of Marpissa marina, a New Zealand jumping spider (Araneae Salticidae). Ethol Ecol Evol 3:79-82. https://doi.org/10.1080/08927014.1991. 9525391

Jackson RR, Pollard SD (1997) Jumping spider mating strategies: sex among cannibals in and out of webs. In: Choe JC, Crespi BJ (eds) The evolution of mating systems in insects and arachnids. Cambridge University Press, Cambridge, pp 340-351

Jakob EM, Marshall SD, Uetz GW (1996) Estimating fitness: a comparison of body condition indices. Oikos 77:61-67. https://doi.org/10. $2307 / 3545585$

Johnson JC, Sih A (2005) Precopulatory sexual cannibalism in fishing spiders (Dolomedes triton): a role for behavioral syndromes. Behav Ecol Sociobiol 58:390-396. https://doi.org/10.1007/s00265-0050943-5

Johnstone RA (1996) Multiple displays in animal communication: 'backup signals' and 'multiple messages'. Philos Trans R Soc B 351:329_ 338. https://doi.org/10.1098/rstb.1996.0026

Kapustjanskij A, Streinzer M, Paulus HF, Spaethe J (2007) Bigger is better: implications of body size for flight ability under different light conditions and the evolution of alloethism in bumblebees.
Funct Ecol 21:1130-1136. https://doi.org/10.1111/j.1365-2435. 2007.01329.x

Lim MLM, Li DQ (2004) Courtship and male-male agonistic behaviour of Cosmophasis umbratica Simon, an ornate jumping spider (Araneae: Salticidae) from Singapore. Raffles Bull Zool 52:435-448

Lim MLM, Li DQ (2007) Effects of age and feeding history on structurebased UV ornaments of a jumping spider (Araneae: Salticidae). Proc R Soc B 274:569-575. https://doi.org/10.1098/rspb.2006.0020

Lim MLM, Li JJ, Li DQ (2008) Effect of UV-reflecting markings on female mate-choice decisions in Cosmophasis umbratica, a jumping spider from Singapore. Behav Ecol 19:61-66. https://doi.org/10. 1093/beheco/arm100

Marentette JR, Fitzpatrick JL, Berger RG, Balshine S (2009) Multiple male reproductive morphs in the invasive round goby (Apollonia melanostoma). J Great Lakes Res 35:302-308. https://doi.org/10. 1016/j.jglr.2009.01.009

Martín J, López P (2015) Condition-dependent chemosignals in reproductive behavior of lizards. Horm Behav 68:14-24. https://doi.org/ 10.1016/j.yhbeh.2014.06.009

Møller AP, Pomiankowski A (1993) Why have birds got multiple sexual ornaments? Behav Ecol Sociobiol 32:167-176. https://doi.org/10. 1007/BF00173774

Neff BD, Svensson EI (2013) Polyandry and alternative mating tactics. Phil Trans R Soc B 368:20120045. https://doi.org/10.1098/rstb. 2012.0045

Painter TS (1913) On the dimorphism of the males of Maevia vittata, a jumping spider. Zool Jahrb Syst 35:625-636

Peaslee AG, Wilson G (1989) Spectral sensitivity in jumping spiders (Araneae, Salticidae). J Comp Physiol A 164:359-363. https://doi. org/10.1007/BF00612995

Peckham EG (1889) Protective resemblances in spiders. Occas Pap Wis Nat Hist Soc 2:61-113

Platnick NI (2018) The world spider catalog, version 19.0. American Museum of Natural History. http://research. amnh.org/iz/spiders/ catalog. Accessed 16 Oct 2018

Richman DB, Jackson RR (1992) A review of the ethology of jumping spiders (Araneae, Salticidae). Bull Br Arachnol Soc 9:33-37

Roulin A (2004) The evolution, maintenance and adaptive function of genetic colour polymorphism in birds. Biol Rev 79:815-848. https:// doi.org/10.1017/S1464793104006487

Ruxton GD, Sherratt TN, Speed MP (2004) Avoiding attack: the evolutionary ecology of crypsis, warning signals and mimicry. Oxford University Press, New York

Sivalinghem S, Kasumovic MM, Mason AC, Andrade MC, Elias DO (2010) Vibratory communication in the jumping spider Phidippus clarus: polyandry, male courtship signals, and mating success. Behav Ecol 21:1308-1314. https://doi.org/10.1093/beheco/arq150

Spencer KA, Buchanan KL, Goldsmith AR, Catchpole CK (2003) Song as an honest signal of developmental stress in the zebra finch (Taeniopygia guttata). Horm Behav 44:132-139. https://doi.org/ 10.1016/S0018-506X(03)00124-7

Stuart-Fox DM, Moussalli A, Marshall NJ, Owens IP (2003) Conspicuous males suffer higher predation risk: visual modelling and experimental evidence from lizards. Anim Behav 66:541-550. https://doi.org/10.1006/anbe.2003.2235

Suter RB, Renkes G (1984) The courtship of Frontinella pyramitela (Araneae, Linyphiidae): patterns, vibrations and function. J Arachnol 12:37-54

Taborsky M, Brockmann HJ (2010) Alternative reproductive tactics and life history phenotypes. In: Kappeler P (ed) Animal behaviour: evolution and mechanisms. Springer, Berlin, pp 537-586. https://doi. org/10.1007/978-3-642-02624-9 18

Taylor LA, McGraw K (2013) Male ornamental coloration improves courtship success in a jumping spider, but only in the sun. Behav Ecol 24:955-967. https://doi.org/10.1093/beheco/art011 
Taylor LA, Clark DL, McGraw KJ (2011) Condition dependence of male display coloration in a jumping spider (Habronattus pyrrithrix). Behav Ecol Sociobiol 65:1133-1146. https://doi.org/10.1007/ s00265-010-1127-5

Taylor LA, Maier EB, Byrne KJ, Amin Z, Morehouse NI (2014) Colour use by tiny predators: jumping spiders show colour biases during foraging. Anim Behav 90:149-157. https://doi.org/10.1016/j. anbehav.2014.01.025

Tedore C, Johnsen S (2014) Visual mutual assessment of size in male Lyssomanes viridis jumping spider contests. Behav Ecol 26:510 518. https://doi.org/10.1093/beheco/aru222

Uetz GW, Papke R, Kilinc B (2002) Influence of feeding regime on body size, body condition and a male secondary sexual character in Schizocosa ocreata wolf spiders (Araneae, Lycosidae): conditiondependence in a visual signaling trait. J Arachnol 30:461-469. https://doi.org/10.1636/0161-8202(2002)030[0461:IOFROB]2.0. $\mathrm{CO} ; 2$

Wells SJ, Ji W, Dale J, Jones B, Gleeson D (2014) Male size predicts extrapair paternity in a socially monogamous bird with extreme sexual size dimorphism. Behav Ecol 26:200-206. https://doi.org/ 10.1093/beheco/aru173
Xiao YH, Zunic-Kosi A, Zhang LW, Prentice TR, McElfresh JS, Chinta SP, Zou YF, Millar JG (2015) Male adaptations to minimize sexual cannibalism during reproduction in the funnel-web spider Hololena curta. Insect Sci 22:840-852. https://doi.org/10.1111/1744-7917.12243

Zamudio KR, Sinervo B (2000) Polygyny, mate-guarding, and posthumous fertilization as alternative male mating strategies. Proc Natl Acad Sci U S A 97:14427-14432. https://doi.org/10.1073/pnas. 011544998

Zurek DB, Cronin TW, Taylor LA, Byrne K, Sullivan ML, Morehouse NI (2015) Spectral filtering enables trichromatic vision in colorful jumping spiders. Curr Biol 25:403-404. https://doi.org/10.1016/j. cub.2015.03.033

Publisher's note Springer Nature remains neutral with regard to jurisdictional claims in published maps and institutional affiliations. 